\title{
Effects of Water Concentration on the Structural and Optical Properties of FTO Thin Films Grown by Home made SISOM'S SPEED technique
}

\author{
Ayodeji OladiranAwodugba ${ }^{1}$ \\ ${ }^{1}$ Department of Pure and Applied Physics, Ladoke Akintola University of Technology, Ogbomoso \\ Nigeria \\ aoawodugba@lautech.edu.ng \\ Gbadebo TaofeekYusuf ${ }^{2}$ \\ ${ }^{2}$ Department of Science Laboratory Technology, Physics Unit, Osun State Polytechnic, Iree, \\ Nigeria \\ hollyusuf@gmail.com
}

\begin{abstract}
Influence of water concentration on the properties of fluorine-doped tin oxide (FTO) thin films was systematically studied in this work. Home made SISOM's SPEED techniques and its chemical formulation was employed to grow the FTO on quartz substrate. Water concentration in the precursor solution was varied from $0,0.5,1.0$ and $1.5 \mathrm{~mol} \%$. The structural, optical, and electrical properties of the films were studied under these deposition conditions. The results show that the properties of the films varied significantly with water concentration. Scanning electron microscopy (SEM) revealed FTO films whose grain size and uniformity increases significantly with increase in water concentration. The structure of the films was measured by X-ray diffraction (XRD) measurement. It shows polycrystalline films with (110), (101), (200), (211) and (220) orientation; the strength increases as water concentration increases. The optical transmission was determined by UV-Vis spectroscopy at 380-780 $\mathrm{nm}$ UV-VIS regions. The optical transmittance varies with water concentration with an average of $84 \%$. The electrical property, measured by Hall Effect revealed ntype semiconductor. The films have the following properties: resistivity, $15 \times 10^{-4} \Omega \mathrm{cm}$; carrier concentration, $18.7 \times 10^{19} \mathrm{~cm}^{-3}$ and mobility of $21.86 \mathrm{~cm}^{2} \mathrm{~V}^{-1} \mathrm{~s}^{-1}$. The average figure of merit, $\varphi$ of the FTO film is 1.25. Optimum deposition condition was established after series of experiments and was found to be $1.5 \%$ water concentration at $460^{\circ} \mathrm{C}$ substrate temperature. The FTO films deposited in this work could be a promising replacement to indium tin oxide (ITO) especially in dyesensitized solar cells.
\end{abstract}

Keywords: Water concentration, Fluorine doped, SPEED, Tin oxide, Properties

\section{Introduction/Background}

Fluorine doped tin oxide thin films (FTO) is widely researched due to its promising structural, optical and electrical properties [1-10]. Many researches have focused on optimization of FTO deposition conditions as a means of improving on its structural, optical, and electrical properties [126]. Among the deposition conditions that are widely optimized in FTO thin films are: substrate temperature, concentration of precursor, water concentration, deposition rate, ageing of precursor, because the properties do depend on deposition techniques [21-26]. Among these conditions, influence of water in the precursor is scantily studied especially for a technique that employs chemical formulation routes to improve on the properties such as SPEED technique [27-29]. However, controllable concentration of water is employed in this research work to improve on the structural, optical and electrical properties of fluorine-doped tin oxide (FTO) films. Water concentration, if well controlled can affect electronic properties of a bulk semiconductor in a significant way just like substrate temperature influences the properties of FTO films [11, 37]. We have previously reported deposition of highly oriented FTO thin films on a glass substrate using varying substrate temperature only $[21,26]$. The range of suitable temperature for growing FTO films was $400-500^{\circ} \mathrm{C}$ and optimum substrate temperature of $460 \mathrm{oC}$ was reported [21]. The quality 
of the resulted films were good though, but more research is essential to further improve on its quality to compete with indium tin oxide (ITO) which is relatively expensive due to scarce element "indium" in ITO compound. ITO is an important candidate in dye sensitized solar cells. Therefore, FTO, due to its abundance and competing optical and electrical properties is a promising alternative to ITO. One important technique widely employed to improve on the quality of FTO in this work is optimization of precursor water concentration.

Many researches have been conducted so far in finding a way to overcome problems associated with FTO thin films through methods especially through fabrication and growth control [3, 2426].The influence of several deposition conditions such as doping concentration, solvent, substrate temperature, etc. on the properties of sprayed FTO films have been studied to determine the optimal deposition conditions to obtain as high electrical conductivity and optical transparency as possible [24-26]. Among the techniques that have been previously employed are: Thermal evaporation [4, 9], Sputtering [11-12], Chemical vapour deposition [13-15], Sol-gel coating [4, 16], Painting [4, 17], Spray pyrolysis [4, 6, 8],Magnetron Sputtering [19], SPEED technique [21, $26,38]$ and Photo chemical vapor deposition [20].Most of the above techniques have produced high quality FTO films. But, there are still few challenges which limit their usage. For instance, magnetron, sputtering and thermal evaporation are good techniques, but they are either expensive due to high vacuum required during deposition or high temperature. The cheaper techniques may not produce high quality films. In contrast, Streaming Process for Electrodeless Electrochemical Deposition Technique (SPEED)patented by SISOM thin films LLC is a promising and pure heterogeneous reaction based which employs water as the primary solvent without the need of expensive vacuum to grow films and it is capable of growing materials at much lower substrate temperatures [26].Therefore, the experimental approach and chemical formulation of SPEED technique has been employed to deposit high quality FTO thin films using controlled amount water concentration.

\section{Materials and Methods}

Fluorine doped tin oxide thin films were grown in this work using home made SISOM's SPEED techniques well as SPEED chemical formulation approach [21]. Analytical grade of $0.5 \mathrm{M}$ of tin (IV) chloride, to act source of tin was mixed with ethanol, isopropanol, methyl propanol. The Fluorine source was $20 \%$ of the tin concentration in the precursor solution. In SPEED chemical formulation, deionized water is one of the major requirements because it is not only employed as a source of oxygen but also as solvent. Therefore, its influence is studied in this work by varying its percentage in the solution as follows: $0,0.5,1$, and $1.5 \mathrm{~mol} \%$. The details of deposition technique by SPEED technique can be found in [21]. Before spraying process continued, the quartz substrates were first degreased rinsed in ethanol and deionized water several times. They were finally dried. The precursor was then sprayed on the clean substrate at a flow rate of $1.2 \mathrm{ml} / \mathrm{min}$ while the substrate temperature $460^{\circ} \mathrm{C}$ of optimized in our previous work was used. The films were deposited at a fixed nozzle-substrate distance (NSD) of $30.0 \mathrm{~cm}$ through the deposition.

Varieties of characterization equipments such as X-ray diffraction, scanning electron microscope (SEM), and optical spectroscopy were used to evaluate the structural and optical properties of the FTO thin films. The band gap of the films was obtained from the absorption edge of the transmittance spectra. The electrical properties of the films were measured with hall coefficient set up.

\section{Results and Discussion}

\subsection{Structural and optical properties}

The structural property of the FTO films grown at different concentration of water is shown by Xray diffraction pattern in fig. 1 . The trend exhibited the structure of polycrystalline tetragonal and made up of multi crystal. 


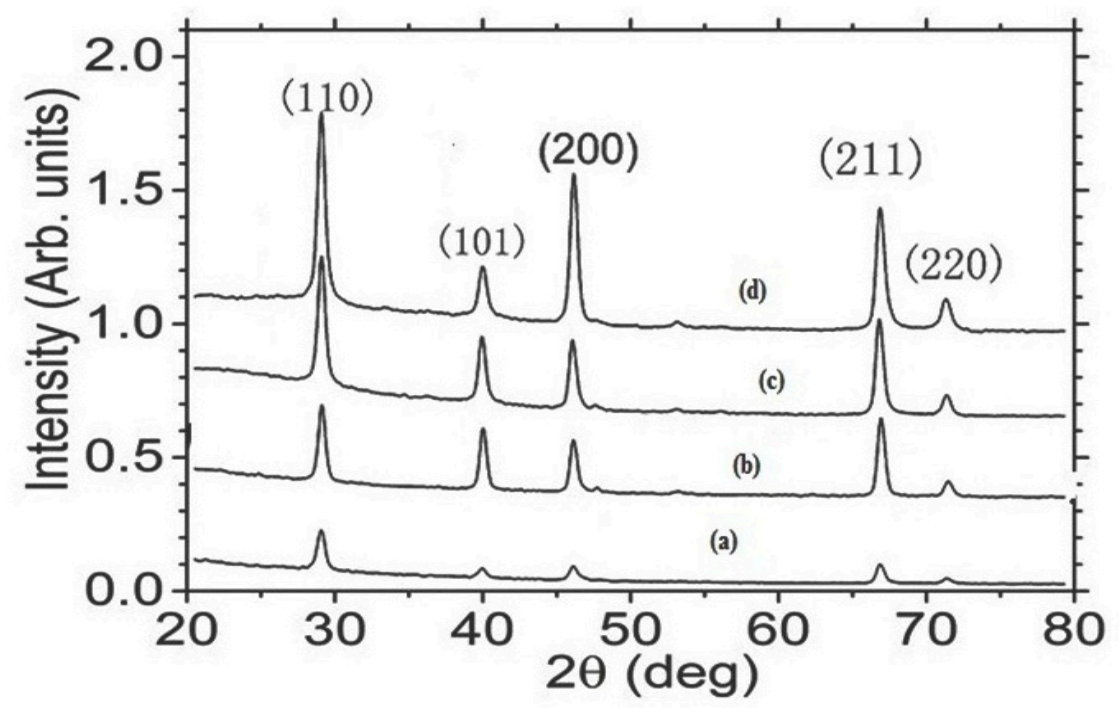

Fig. 1: X-ray diffraction patterns of the FTO films prepared by addition of different quantities of $\mathrm{H}_{2} \mathrm{O}$ (a) $0 \mathrm{~mol} \%$ (b) $0.5 \mathrm{~mol} \%$ (b) $1.0 \mathrm{~mol} \%$ (c) $1.5 \mathrm{~mol} \%$

The structural orientation consists of (110), (101), (200), (211) and (220) and its strength increases as water concentration increases. The strength of 110 structural orientations appears more conspicuous than other orientations. When the water concentration was increased to $1.0 \mathrm{~mol} \%$, there is drastic increase in all orientations and continues until $1.5 \mathrm{~mol} \%$. The sharp diffraction peaks indicates that the crystals in the tin oxide film are relatively large.FTO thin films deposited at 0 mol $\%$ shows relatively short diffraction which indicates the film's poor crystallinity. Generally, the film's crystallinity increases with water concentration. The poor crystallinity may be due to the incomplete formation of the FTO film at $0 \mathrm{~mol} \%$ water concentration. It is seen from fig. 1 that improvement on the crystallization of FTO films starts to commence typically after 0.5 to $1.5 \mathrm{~mol} \%$ water concentration.

The SEM images of FTO thin films prepared with in different water concentrations are shown in Fig. 2. Starting from fig. 2 (a), that is, the film grown with $0 \mathrm{~mol} \%$ water concentrations, the film's grain sizes are relatively small, not compact and contained few holes on surface of the thin films.
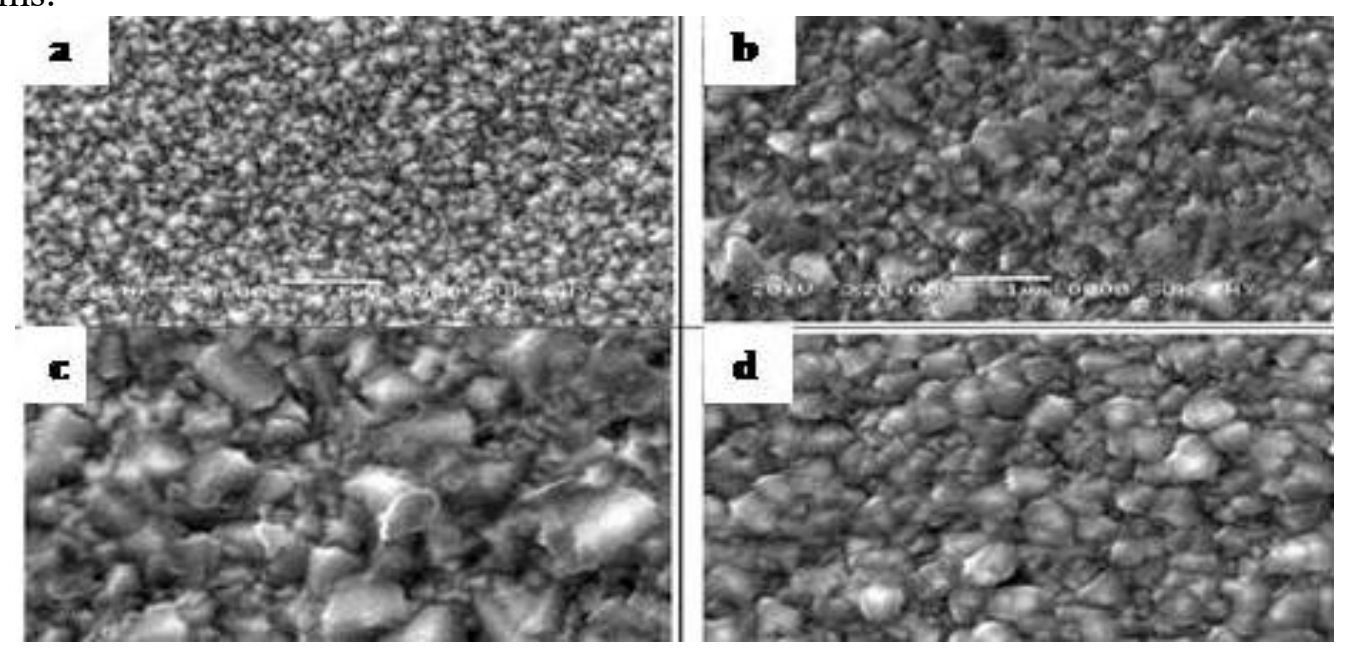

Fig. 2: Morphology of FTO films prepared by adding different $\mathrm{H}_{2} \mathrm{O}$ quantities of (a) 0 mol\%, (b) $0.5 \mathrm{~mol} \%$, (c) $1 \mathrm{~mol} \%$, (d) $1.5 \mathrm{~mol} \%$.

Obviously, the grain size increases as water concentration increases. Different surface morphologies of the thin films can be attributed to different nucleation and growth mechanisms at different water concentration. The nucleation and growth habit of polar FTO crystal under 
hydrothermal condition has been investigated by many researchers especially in $\mathrm{ZnO}$ thin films [37]. The polarity and saturated vapor pressure of the solvents, precursor, reaction temperature and time, and solution basicity have significant effects on the surface morphology of the films [37]. At $1 \mathrm{~mol} \%$ water concentration, the thin films continue to grow and exhibits larger grains of various sizes on the surface of the substrate (see Figure 2(b). With increasing water concentration to $1.5 \mathrm{~mol} \%$, the substrate becomes well covered with presence of nanoagglomerations along the entire surface of the substrate as seen in Figure 2(c), the grain size also increases in size and reached the maximum. Beyond this water concentration $(1.5 \mathrm{~mol} \%)$, "the substrate becomes completely covered with uniform grain size of FTO thin films showing that nanoagglomerations continue its formation to become micro agglomerations at the top of the sample surface" [37]. The FTO thin film is highly oriented at $1.5 \mathrm{~mol} \%$ with average diameter of $100 \mathrm{~nm}$. When the water concentration increases, the crystal grains grew larger and the crystal interfaces decreases [37]. Furthermore, the density, and order degree of the FTO nanorods were the maximum at $1.5 \mathrm{~mol} \%$ water concentration. This observation is consistent with XRD findings described above (fig.1).Formation of FTO films could take place through two mechanisms when optimizing water concentration [11]. The first mechanism is breaking of chemical bond at high temperature. The following equation is the doping equation:

$\mathrm{Sn}(\mathrm{OH})+4 \mathrm{NH}_{4} \mathrm{~F}+3 \mathrm{OH} \longrightarrow \mathrm{SnF}_{4}+4 \mathrm{H}_{2} \mathrm{O}+4 \mathrm{NH}_{3}$

From equation (1) above, it is seen that water is one of the by products of the reaction. Hence, it has to be decomposed and volatilized to bring about quality films. This is where deposition temperature actually becomes important. If the deposition temperature is not sufficiently high enough to decompose and volatize bye products, the resulting films may have poor adherence to the substrates, and hence may affect the films' quality. On the other hand, too high temperature may degrade film's quality. Therefore, the study of water concentration and deposition temperature is very crucial if high quality films are in need.

In our previous research work [21], substrate temperature was optimized between the deposition temperature ranges of 440 to $500^{\circ} \mathrm{Cand} 20 \%$ water concentration. The substrate temperature of $460^{\circ} \mathrm{C}$ was the optimum temperature. At temperatures below or above this, heterogeneous reaction of the film was activated, and hence, the films' quality was enhanced. Since both substrate temperature and water concentration are complementary and play a significant role in films, then both parameters deserve to be investigated jointly. In our previous work, the films grown at $460^{\circ} \mathrm{C}$ appeared more uniform, shiny and adhered strongly to the substrates than other temperatures. But, more research is required to further improve on its quality determining film's quality. The primary objective is to provide an alternative to ITO which is no longer suitable for DSSC solar cells due to scarcity of indium which makes up the ITO compound as discussed in the introduction section of this work. The average figure of merit of 1.25 was determined in equation (2).A detail of figure of merit for individual water concentration is shown on table 1.

Figure of merit $(\varphi)=\mathrm{T}^{10} / \mathrm{R}_{\mathrm{s}}$

Where $T$ is the transmittance in the visible range and $\mathrm{R}_{\mathrm{s}}$ is the sheet resistance.

The unprecedented improvement observed in the structural, optical and electrical properties of FTO films in this work is attributable to action of water in the precursor. Water can promote the cleavage of the chemical bonds in MBTC. According to SPEED chemical formulation [MRS] "substrate kT must exceed the heterogeneous reaction activation energy and be sufficient to decompose and volatilize the reaction byproducts, formation of attached $\mathrm{SnO}_{2}$ in Eq. (2) are followed by site regeneration" according to the following equation:

$[\mathrm{Sub}] \mathrm{SnO}_{2}+\mathrm{OH}^{-} \rightarrow[\mathrm{Sub}] \mathrm{SnO}_{2}(\mathrm{OH})$

$[\mathrm{Sub}] \mathrm{SnOH})^{3+}+4 \mathrm{NH}_{4} \mathrm{~F}+3 \mathrm{OH}^{-}$

$\longrightarrow \mathrm{Sub}] \mathrm{SnF}_{4}+4 \mathrm{H}_{2} \mathrm{O}+4 \mathrm{NH}_{3}$ 
"Growth of $\mathrm{SnF}_{4}$ molecules occur randomly during growth". F on the O lattice site is a donor. With water and solvent ligand, the adsorbed complex undergoes hydroxyl-ion-assisted reduction to form attached Sn [12], which paired with the oxygen vacancy acts as a donor [6]. Water does not participate in the reaction and $\mathrm{O}$ vacancies occur via adsorption of the tin complex

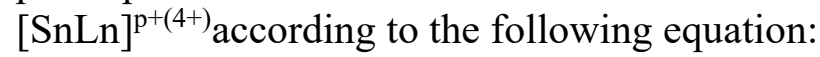

$[\mathrm{Sub}][\mathrm{SnLn}]^{\mathrm{p}+(4+)}+\mathrm{mOH}^{-} \longrightarrow[\mathrm{Sub}] \mathrm{Sn}+\mathrm{m}(\mathrm{OHLn})$.

According to above equation, when the concentration of water in the product reaction is low more fluorine ions are ejected into the lattice of tin oxide. The fluorine should occupy the oxygen ions due to comparable ionic size and bond energy, this gives rise to reduction in Coulomb forces that bind the lattice together. Since the "charge on $\mathrm{F}$ is only half of the charge on $\mathrm{O}^{2-}$ and thus geometrically, the lattice is nearly unable to distinguish between fluorine ions and oxygen ions" [11-36].

The UV-Visual light transmission curves of FTO films prepared with different $\mathrm{H}_{2} \mathrm{O}$ concentrations are shown in fig. 3 .

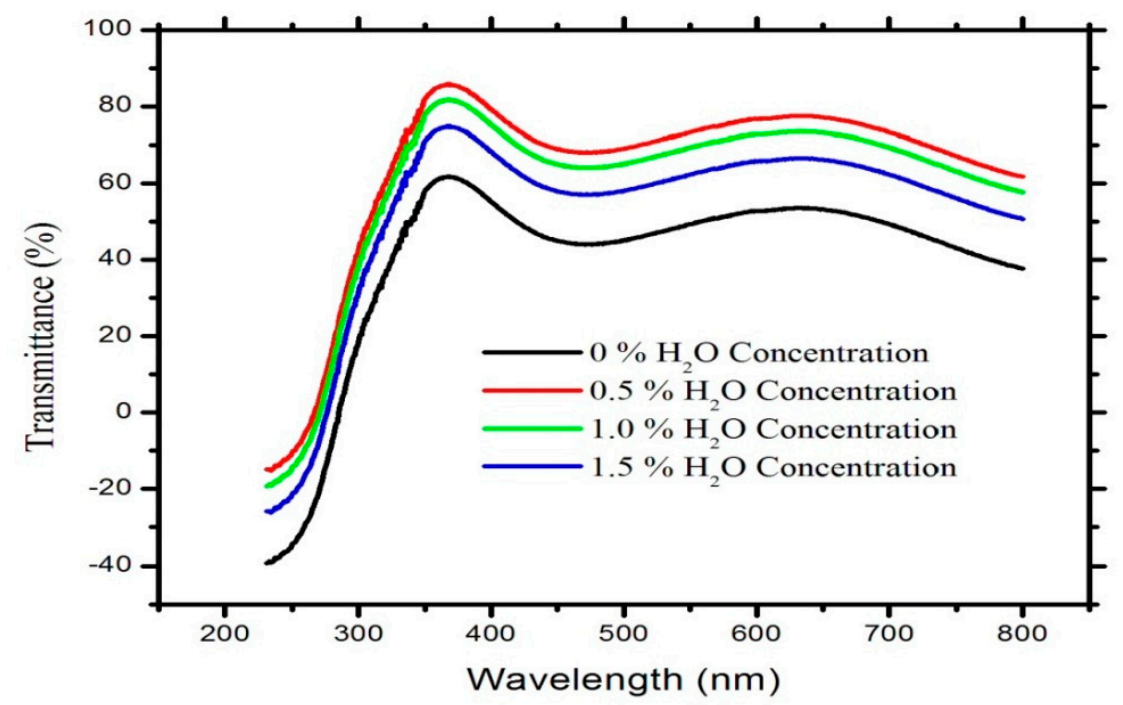

Fig. 3: UV-Visual light transmission of FTO films prepared by adding different quantities of $\mathrm{H}_{2} \mathrm{O}$ (a) $0 \mathrm{~mol} \%$ (b) $0.5 \mathrm{~mol} \%$ (c) $1.0 \mathrm{~mol} \%$ (d) $1.5 \mathrm{~mol} \%$

The results showed that, with increase of $\mathrm{H}_{2} \mathrm{O}$ concentration, the visible light transmission of the films changed slightly. In the region of 380-780 nm, the average transmission rate was about $84 \%$. As shown in the transmission curves in fig. 3, light at $284 \mathrm{~nm}$ was absorbed completely by all the films, because the ultraviolet light was absorbed by the electron transition from the valence band to the conduction band. Due to the interference of the film, the transmission curves showed fluctuation and wave-like pattern.

Table 1 shows the thickness and optical band gap of FTO tin films grown at different water concentration. The film thickness decreases from 411 to $1007 \mathrm{~nm}$. The changes of thickness of the FTO film prepared at various water concentrations were determined by SEM image in fig. 2. The results indicated that the thickness increased with water concentration [37]. This may be attributed to activation energy which is closely related to the deposition rate of the films. "With increased water concentration, the activation energy may likely decrease" [37]. It also shows the band gap of the FTO films. The band gap decreases steadily with water concentration. The maximum is achieved at $0 \%$ and minimum at $1.5 \%$. From these results, varying the quantity of water in the precursor solution is a way of improving on the properties of FTO. 
Table 1: Properties FTO films deposited at various water concentrations

$\mathrm{H}_{2} \mathrm{O}$ Conc. (\%) Thickness (nm) Band gap (Ev)

$\begin{array}{lll}0 & 411 & 3.79 \\ 0.5 & 744 & 3.62 \\ 1.0 & 901 & 3.54 \\ 1.5 & 1007 & 3.16\end{array}$

\subsection{Electrical properties}

The relationship between free carrier concentration $(\mathrm{n})$, mobility $(\mu \mathrm{H})$ and resistivity $(\rho)$ at various water concentrations is shown in fig. 4 . The optimum mobility, carrier concentration and resistivity are $21.86 \mathrm{~cm}^{2} \mathrm{~V}^{-1} \mathrm{~s}^{-1}, 18.7 \times 10^{19} \mathrm{~cm}^{-3}$ and $15 \times 10^{-4} \Omega \mathrm{cm}$ respectively. These values fall at 1.5 mol\% of water concentration. This indicates that $1.5 \mathrm{~mol} \%$ of water concentration is the best deposition condition for achieving the best photovoltaic performance. The hall measurements indicate the FTO films to be of n-type semiconductors.

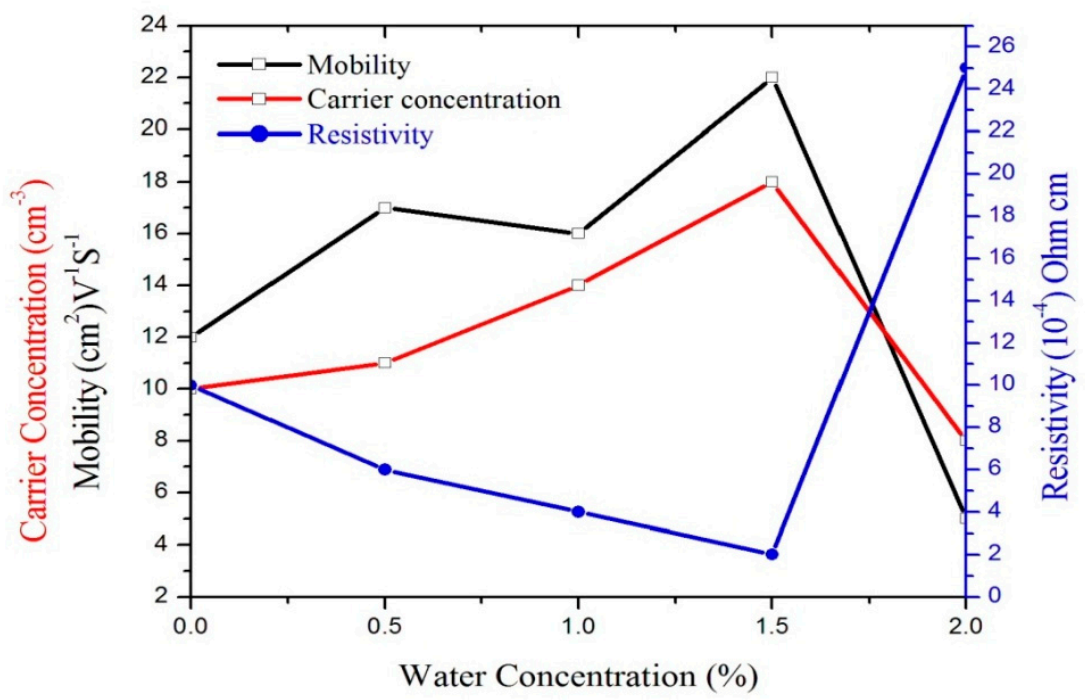

Fig. 4: Variation in carrier density $(\mathrm{N})$, Hall mobility $\mu_{\mathrm{H}}$, and resistivity $(\rho)$

Table 2 shows the sheet resistance and figure of merit of the FTO films grown at different water concentrations. The sheet resistance decreases as water concentration increases, it remained constant when the water concentration exceeded $1.5 \mathrm{~mol} \%$. It is found to decrease from 20.5 to $8.2 \Omega$. The average figure of merit calculated is 1.25 .

Table 2: Sheet resistance and figure of merit of FTO films deposited at various water concentrations

$\mathrm{H}_{2} \mathrm{O}$ Conc. (\%) Sheet res. ( $\left.\mathrm{\Omega}\right)$ Figure of merit $(\phi)$

\begin{tabular}{lll}
\hline 0 & 20.5 & 1.08 \\
0.5 & 15.6 & 1.14 \\
1.0 & 11.9 & 1.18 \\
1.5 & 8.2 & 1.60 \\
\hline
\end{tabular}




\section{Conclusion}

In this work, the structural, optical and electrical properties of FTO films were investigated as a function of water concentration. Home made SPEED technique was used to grow FTO films. The properties of the films were controlled by varying the concentration of water in the precursor solution. The structural, optical and electrical properties of the films depend on water concentration. The crystallinity of FTO films increases with water concentration. The SEM, transmission and electrical properties measurement revealed FTO films whose quality improves as water concentration increases. The average transmittance of the deposited thin films was about $84 \%$ in the region of 380-780 nm. Hall mobility $\mu \mathrm{H}$, carrier density $(\mathrm{N})$ and resistivity $(\rho)$ of FTO films measured under various water concentrations are $21.86 \mathrm{~cm}^{2} \mathrm{~V}^{-1} \mathrm{~s}^{-1}$ and $18.7 \times 10^{19} \mathrm{~cm}^{-3}$ and $15 \times 10^{-4} \Omega \mathrm{cm}$ respectively at $1.5 \mathrm{~mol} \%$ of water concentration. The FTO films' average figure of merit is 1.25 . The FTO films, according to hall measurements indicate n-type semiconductors. The FTO deposited in this work is a promising replacement to indium tin oxide (ITO) in solar cells application.

\section{References}

[1] C.G.V. Walle, Theory of Hydrogen-Related Levels in Semiconductors and Oxides Phys. Rev. Lett. 85. 012(2000).

[2] K, Endrowedne, H., Deok-Woo., S., Youl-Moon, S., Jae-Eun., H., Chi-Hwan. Structure and thermal properties of transparent conductive nanoporous $\mathrm{F}: \mathrm{SnO}_{2}$ films. Thin Solid Films 517, 4211-4214 (2009).

[3] A., Martinez, D.R. Acosta FTO Films for Solar Cell Applications. Thin Solid Films, 483 107-111 (2005).

[4] A. Masuda,. Yoshitake, B., Ohji, N., Tatsuki, H., Kato, N., Kazumi, B., Aqueous Phase Deposition of Dense Tin Oxide Films with Nano-Structured Surfaces. Scitech Connect 128-134 (2014).

[5] G. J. Exarhos and X. D. Zhou, Discovery-based design of transparent conducting oxide films Thin Solid Films 515, 7025 (2007).

[6] R.J. Deokate., Pawar, S.M., Moholkar, A.V., Sawant; V.S., Pawar; C.A., Bhosale, C.H., Rajpure, K.Y., (2008). Spray Deposition of Highly Transparent Fluorine Doped Cadmium Oxide Thin Films. Mater. Res. Soc., 32, 242-350.

[7] A. A. Yadav, E. U. Masumdar, A. V. Moholkar, M Neumann-Spallart, K. Y. Rajpure and C. H. Bhosale. Effect of Quantity of Spraying Solution on the Properties of Spray Deposited Fluorine Doped Tin Oxide Thin Films. J. Alloys and Compounds 448, 350 (2009).

[8] B. Thangaraju, Fabrication of High-Performance Fluorine Doped-Tin Oxide Film Using Spray Pyrolysis. Thin Solid Films 402, 71 (2002)

[9] A. Goetzberger and C. Hebling, Photovoltaic materials, past, present, future Sol. Energy Mater. Sol. Cells 62, 1 (2000).

[10] G. Frank, E. Kaur and H. Kostlin, Transparent heat-reflecting coatings for solar applications based on highly doped tin oxide and indium oxide Sol. Energy Mater. 8,387 (1983).

[11] Z., Hongli, Qiying, L., C, Yongxiu, Z., Fucheng, (2008). Effects of Water on the Structure and Properties of F-Doped $\mathrm{SnO}_{2}$ Films. Materials Letters 62, 1294-1296.

[12] S. Chen, Low emissivity coatings for the improvement of the insulation properties of double-glazing units. Thin Solid Films 77, 127 (1981).

[13] Chung, Wan-Young, et al. "Tin oxide micro sensor for LPG monitoring." Sensors and Actuators B: Chemical 20.2-3 139-143 (1994):

[14] J.R., Brown, et al. "Response behaviour of tin oxide thin film gas sensors grown by MOCVD." Sensors and actuators B: Chemical 63.1 109-114 (2000).

[15] P. Nelli, G. Faglia., G. Sberveglieri, E. Cerede, G. Gabetta, A. Dieguez and J. R. Morante, The aging effect on $\mathrm{SnO}_{2}-\mathrm{Au}$ thin film sensors: electrical and structural characterization. Thin Solid Films 371, 249 (2000). 
[16] Q. Zhao, et al. Tailoring of textured transparent conductive $\mathrm{SnO}_{2}: \mathrm{F}$ thin films. Journal of ' Alloys and Compounds (15) 427-431(2013).

[17] D., Tatar, \& B. Düzgün. The relationship between the doping levels and some physical properties of $\mathrm{SnO}_{2}: \mathrm{F}$ thin films spray-deposited on optical glass - J Phys 79: 137. doi:10.1007/s12043-012-0288-3 (2012).

[18] A. C. Arias, L. S. Roman, T. Kugler, R. Toniola, M. S. Meruvia and I. A. Hummelgen, The relationship between the doping levels and some physical properties of $\mathrm{SnO}_{2}: \mathrm{F}$ thin films spray-deposited on optical glass. Thin Solid Films 371, 201 (2000).

[19] P. S. Shewale, S. I. Patil and M. D. Uplane. Preparation of fluorine-doped tin oxide films at low substrate temperature by an advanced spray pyrolysis technique, and their characterization Semicond. Sci. Technol. 25 (11) (2010).

[20] M. Ruske, G. Brauer and J. Szczrbowski, Thin Solid Films 351, 146 (1999)

[21] F., Khalilzadeh, I., Oladeji, G.T., Yusuf, J., Nath, N., Nader, S., Vangala, Cleary. W., A.O. Awodugba, \& R.; Peale, R. Optical and Electrical Properties of Tin Oxide Based Thin Films Prepared By Streaming Process for Electrodeless Electrochemical (SPEED). MRS Spring Meeting. MRS15-2136423.R1.1-7 (2015).

[22] P.J., Kelly, R.D Arnell, Magnetron Sputtering: A Review of Recent Developments and Applications. Vacuum Volume) 159-172(2000).

[23] F. Homma, C., Kentjana, \& M., Mooney. Optics for High-Brightness Synchrotron Radiation Beamlines. California SPIE Vol. 1740, 95-103 (1992).

[24] Garcia, M., Maldonado, Castaneda, L., Silva- Gonzalez, R., \&Olvera, M.L.SnO 2 Thin Film Gas Sensor Vol. 4, 61-72(2014).

[25] M., Kenji, N., Kiyofumi, K., Shoji. Initial Growth of $\mathrm{SnO}_{2}$ Thin Film on the Glass Substrate Deposited By the Spray Pyrolysis Technique Thin Solid Films 515, 8632-8636 (2010).

[26] G.T., Yusuf, et al., Characteristics of Fluorine-doped tin oxide thin films grown by Streaming process for Electrodeless Electrochemical Deposition. APS April Meeting 2015, abstract \#L1.056

[27] G.T. Yusuf, B.K. Babatunde. A.D. Ishola, S.R., Oladimeji, A.A. Adedeji, J.T. Adeleke. Science and Engineering Applications1 (7) 92-95(2016).

[28] G.T. Yusuf, H.O. Efunwole, M.A. Raimi, O.E. Alaje and A.K. Kazeem. Effect of Al and Mg Doping on Optical Properties of $\mathrm{ZnO}$ Thin Films Prepared by Spin Coating DOI: 10.15415/jnp.2014.21005 (2014).

[29] G.T., Yusuf, \& Efunwole, H.O. Effects of Dimethylamine (DMA) and Ethylenediaminetetraacetic Acid (EDTA) on Optical, Structural And Morphological Properties of Zinc Oxide Thin Films Prepared By Chemical Bath Deposition Technique Int. Journal of Scientific \& Technology Research 1(8), 24- 27(2012).

[30] D., Perednis, \& L.J., Gauckler. J Thin Film Deposition Using Spray Pyrolysis Electroceram 14: 103. doi:10.1007/s10832-005-0870-x (2005).

[31] R.N., Arle, B.L., Khatik. Effect of Volume Spray Rate on Highly Conducting Spray Deposited Fluorine Doped $\mathrm{SnO}_{2}$ Thin Films IJCPS Vol. 3 Special Issue - NCETNN 83-88 (2014).

[32] B.D., Cullity. Elements of X-Ray Diffraction, Addison-Wesley Publishing Company Mater. Res. Soc., 32, 242-247 (1978).

[33] E.V.A., Premalal. N., Dematage, S., Kaneko, A., Konno. Preparation of High Quality Spray-Deposited Fluorine-Doped Tin Oxide Thin Films Using Dilute Di (N-Butyl) Tin (IV) Diacetate Precursor Solutions. Thin Solid Films 520, 6813-6817. (2012).

[34] C-J., Li, C-X, Li, M. Wang. Effect of Spray Parameters on the Electrical Conductivity of Plasma-Sprayed La1-Xsrxmno3 Coating for the Cathode of SOFCS. Surface and Coatings Technology. Surface and Coatings Technology. 198: 278-282 (2005). 
[35] A. R. Babar, S. S. Shinde, A. V. Moholkar, C. H. Bhosale, and K. Y. Rajpure. Structural and optoelectronic properties of sprayed $\mathrm{Sb}: \mathrm{SnO} 2$ thin films: Effects of substrate temperature and nozzle-to-substrate distance Journal of Semiconductors 32(10) 1-9 (2011).

[36] Elangovan, Singh, M.P., Ramamurthy, K. (2004).Solar cell Materials. Mater. Sci. Eng. B 113 (2004) 143.

[37] H., Zhao, Q., Liu, Y. Cai and F. Zhang. Influence of Water on Fluorine-Doped Tin Oxide Films. American Ceramic Society Bulletin, Vol. 86, No. 6.

[38] R. E. Peale,E. Smith,H. Abouelkhair,I.O., Oladeji,S., Vangala,T., Cooper.,G. Grzybowski,F. Khalilzadeh-Rezaie and J.W. Cleary. Electrodynamic properties of aqueous spray-deposited $\mathrm{SnO}_{2}: \mathrm{F}$ films for infrared plasmonics. Optical Engineering 56(3), 037109 (March 2017), 